\title{
DEVELOPMENTAL POSTERIOR DISLOCATION OF THE RADIAL HEAD
}

\author{
CHRISTOPHER J. GOOD, MALCOLM H. WICKS \\ From Queen Mary's Hospital for Children, Carshalton, St George's Hospital, London, and the Southwest Metropolitan \\ Regional Orthopaedic Training Scheme
}

\begin{abstract}
We describe two boys with bilateral deformity of the upper end of the radius. The condition appears to predispose to non-traumatic posterior dislocation of the radial head and is associated with posterior bowing of the upper end of the ulna. This problem has not been previously described.
\end{abstract}

In this paper we describe four elbows with varying degrees of deformity of the radial head occurring in two growing boys. This deformity is associated with subluxation or dislocation of the radial head and posterior bowing of the upper end of the ulna. The four elbows present a spectrum of severity and suggest that the deformity is progressive, similar to Madelung's deformity but at the proximal end of the radius and ulna. In an extensive review of the literature we have found only one other report of a similar deformity (Gunn and Pillay 1964). These authors did not draw any conclusions about an underlying disorder of the radial head growth plate and its possible relationship to posterior dislocation.

\section{RADIOGRAPHS}

The radiographs obtained (Figs 1 to 8 ) have been placed in increasing order of severity. They range from slight radial head dysplasia and mild subluxation in Figures 1 and 5 to severe deformity in Figures 4 and 8. Figures 2 and 3 and Figures 6 and 7 show intermediate stages of the deformity and the trend to dislocation. This is particularly noticeable in the lateral views (Figs 5 to 8 ).

\section{CASE REPORTS}

Case 1. A fit boy, aged 16 years, presented with a prominence on the lateral side of his left elbow. This had developed over a period of three to four years and did not interfere with normal function. It caused discomfort when leaned upon. There was no history of trauma or of similar deformity in the family.

On examination there was a lump the size of a golf ball over the posterolateral aspect of his left elbow and a similar but smaller prominence on the other elbow (Fig. 9). There was no deformity of the forearm or wrist. Wrist movements were normal but all movements were restricted in both elbows. Flexion was irom 18 degrees to 140 degrees on the left and from 5 degrees to 145 degrees on the right. Pronation was limited to 40 degrees on the left and 50 degrees on the right. Supination was to 50 degrees on the left and 70 degrees on the

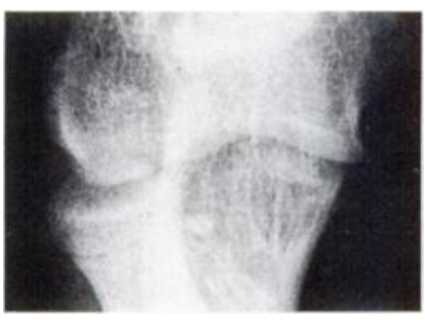

Fig. 1

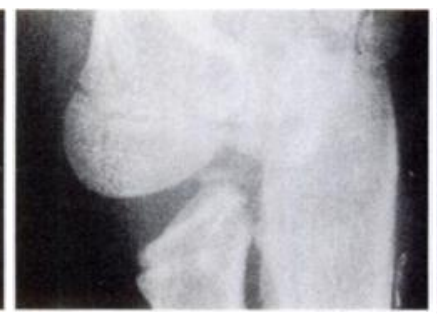

Fig. 2

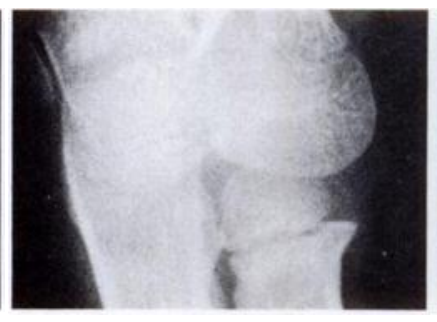

Fig. 3

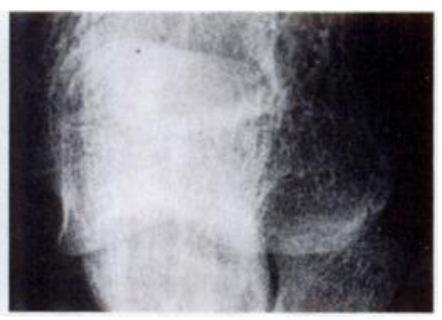

Fig. 4

Anteroposterior views of elbo:vs arranged in increasing order of severity. Figure 1-Right elbow (Case 1). Figure 2-Right elbow (Case 2). Figure 3-- Left elbow (Case 2). Figure 4-Left elbow (Case 1).

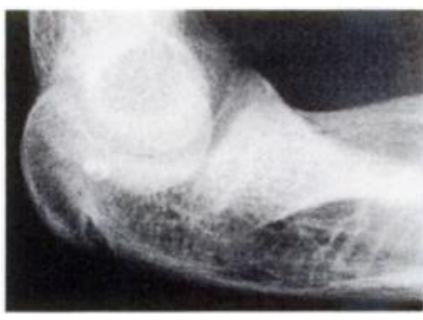

Fig. 5

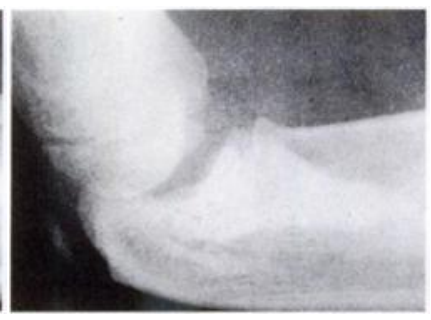

Fig. 6

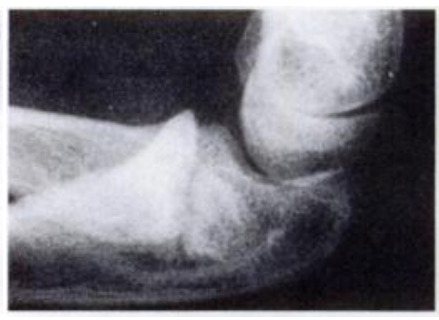

Fig. 7

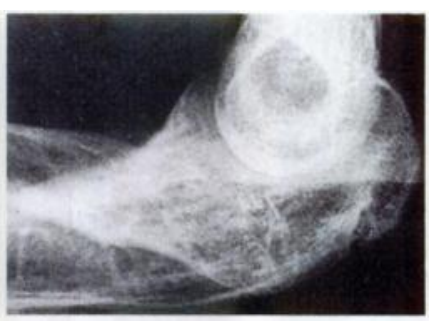

Fig. 8

C. J. Good, FRCS, Senior Orthopaedic Registrar

St George's Hospital, Blackshaw Road, London SW17, England.

M. H. Wicks, FRACS, Orthopaedic Surgeon

12 Tarlton Street, Somerton Park, South Australia 5044.

Requests for reprints should be sent to Mr C. J. Good.

(C) 1983 British Editorial Society of Bone and Joint Surgery $0301-620 \mathrm{X} / 83 / 1001-0064 \$ 2.00$

Lateral views of elbows arranged in increasing order of severity. Figure 5-Right elbow (Case 1). Figure 6 - Right elbow (Case 2). Figure 7Left elbow (Case 2). Figure 8-Left elbow (Case 1). 
right. The apparent carrying angle was 20 degrees on the left compared with eight degrees on the right.

Radiographs showed subluxation of the right radial head and dislocation of the left (Figs 1, 4, 5 and 8). The right radial head epiphysis had almost fused, was discoid in shape and tilted in an anterolateral direction. That on the left had fused and had a domed-shaped head. In both elbows the capitellum was dysplastic and the ulna posteriorly bowed.

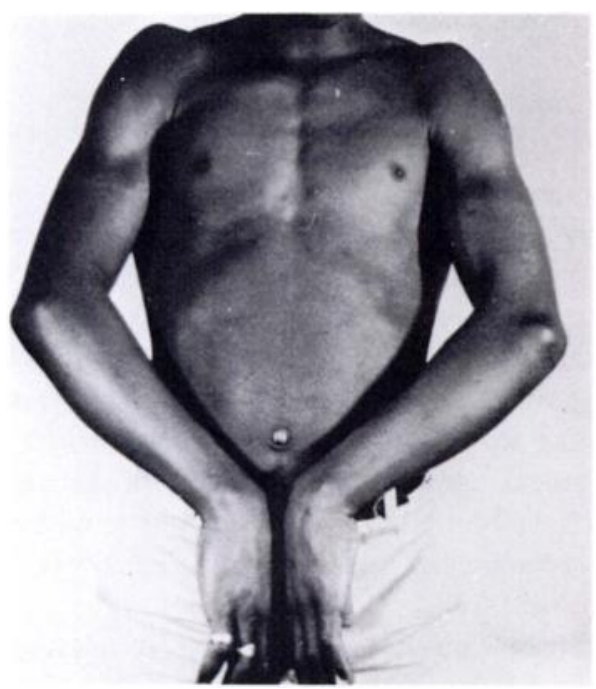

Fig. 9

Case 1. Showing prominent radial heads.

Case 2. A fit boy, aged 12 years and entering his growth spurt at the time of presentation, complained that he was unable to move his left hand into the higher positions when playing the violin (these positions require increasing supination). There was no difficulty with other activities or with sport. There was no problem with the other arm and no history of trauma. The parents remarked that the paternal grandfather might have had a similar problem.

There was no visible deformity in either elbow, forearm or wrist. Wrist and elbow movements were normal, as was the carrying angle on each side. Rotation of both forearms was reduced. Pronation was limited to 45 degrees on the left and 50 degrees on the right. Supination was limited to 60 degrees on both sides.

Radiographs showed subluxation of both radial heads, with the left one more advanced than the right (Figs 2, 3,6 and 7). The right radial head epiphysis was discoid and slanted in an anterolateral direction with some posterior bowing of the ulna and a dysplastic capitellum. The left radial head epiphysis was shaped like a truncated cone. The epiphysial plate was horizontal and deficient anteriorly. In addition the ulna was posteriorly bowed and the capitellum dysplastic.

Review one year later showed that the clinical examination had not changed. Further radiographs showed that the radial head epiphyses had begun to fuse but that the anomalies described above had not changed.

\section{DISCUSSION}

We have described two boys demonstrating abnormalities in four elbows. In neither case was there a history to suggest non-accidental injury in infancy nor was there any clinical evidence of epiphysial or metaphysial abnormality in other joints.
These elbow deformities differed in severity but were of the same aetiology. We suggest that the phrase "congenital dislocation of the radial head" should be reserved for those elbows in which the dislocation is present at birth as such dislocations are usually associated with other disorders (Mardam-Bey and Errol Ger 1979). The deformity we described is a developmental dislocated head of the radius, beginning about puberty and becoming symptomatic during early adolescence. The predisposition to develop this abnormality must be inherited as it has a familial tendency (Case 2; Gunn and Pillay 1964) and is bilateral with varying penetrance.

The deformity is primarily an abnormality of growth of the proximal radial growth plate. In two elbows the abnormality was on the metaphysial side resulting in a disc-like epiphysis slanted in a volar and lateral direction (Figs 1, 2, 5 and 6). One elbow had the abnormality on the epiphysial side such that the growth disc was horizontal and the epiphysis was deficient anteriorly but overgrown posteriorly (Figs 3 and 7). The fourth elbow showed the mature lesion of full "developmental dislocation of the radial head" (Figs 4 and 8 ).

It is tempting to compare this with Madelung's deformity: "a developmental abnormality of the wrist characterised by dorsal and lateral bowing of the distal radius, shortness of the radius and abnormal growth of the distal radial epiphysis. The distal articular surface tilts ulnarward and volarward." (Edmonson and Crenshaw 1980).

The four elbows presented show a progression in radiological severity and suggest that dislocation is the extreme stage of the deformity. If this is correct then the existence of unilateral dislocation is reasonable. Case 1 at 16 years of age showed the mildest stage in the right elbow (Figs 1 and 5) and the severest stage of dislocation in the other one (Figs 4 and 8). As the epiphysis had nearly fused on the right side then the end result was a unilateral dislocation.

We would therefore propose a classification for radial head dislocation to include this hitherto unrecognised anomaly. This is presented in Table $\mathrm{I}$.

Table I. Classification of posterior radial head dislocation

\begin{tabular}{|ll|}
\hline 1. Congenital & $\begin{array}{l}\text { a. Isolated } \\
\text { b. Associated with other disorders }\end{array}$ \\
\hline 2. Developmental & $\begin{array}{l}\text { a. Unilateral } \\
\text { b. Bilateral }\end{array}$ \\
\hline 3. Traumatic & \\
\hline
\end{tabular}

Although we have described the deformity and its relationship to posterior dislocation we feel a similar mechanism may result in dislocation in other directions.

We would like to thank Mr A. G. Apley and Mr Geoffrey Walker for their help in the preparation of this paper. Our cases were under the care of Mr R. Bendall and Mr Geoffrey Walker and we are grateful to them for permission to use them for this report.

\section{REFERENCES}

Edmonson AS, Crenshaw AH, eds. Campbell's operative orthopaedics. 6th ed. St Louis: C. V. Mosby, 1980:1972.

Gunn DR, Pillay VK. Congenital posterior dislocation of the head of the radius. Clin Orthop 1964;34:108-13.

Mardam-Bey T, Errol Ger MD. Congenital radial head dislocation. J Hand Surg 1979;4:316-20. 